\title{
Research on the Emission Reduction Problem of Biomass Power Generation
}

\author{
Xin Wang ${ }^{1, ~ a, ~ C h e n j u n ~ S u n ~}{ }^{2, b}$, Zhuhan Long ${ }^{1, ~ c}$, Lilin Peng ${ }^{1, d}$ and Ming Zeng ${ }^{1, e}$ \\ ${ }^{1}$ School of North China Electric Power University, Beijing 102206, China; \\ ${ }^{2}$ State Grid Hebei Electric Power Company, Shijiazhuang 050000, China. \\ awangirl1002@163.com, bscj@he.sgcc.com.cn, c532300376@qq.com, dpenglilinbj@126.com, \\ e921735063@qq.com
}

\begin{abstract}
Biomass energy belongs to low carbon energy, and it plays an important role in gradually changing China's energy structure dominated by fossil fuels. Therefore, research on low carbon issues of biomass power has great significance in application and planning of biomass. Firstly, this paper puts forward the low carbon contribution degree of biomass power generation and its evaluation method; secondly, with the theoretical and empirical combination, it analyzes the emission reduction contribution degree of biomass power generation technology; finally, the cost-effectiveness of emission reduction of biomass power generation has been comprehensively studied. And this paper lays the theoretical foundation for the biomass power generation project to carry out.
\end{abstract}

Keywords: Biomass power generation; Emission reduction contribution degree; The cost-effectiveness of emission reduction; Emission reduction risks.

\section{Introduction}

The broad sense of biomass energy includes all the energies based on the biomass, and has the characteristic of renewable.

China's main biomass energy resources are agricultural wastes, forest product residues, livestock manure, urban living garbage and organic waste residue and wastewater. It is estimated that the total amount of biomass energy resources that can be developed in China is about 0.7 billion tons of standard coal. Agricultural wastes are widely distributed. The annual output of agricultural straw is 0.72 billion tons, of which 0.6 billion tons can be used as energy, equivalent to 0.3 billion tons of standard coal; the sources of fuelwood mainly include forest harvesting, forest cutting and firewood forest. The survey shows that China's average annual production of fuelwood is about 0.127 billion tons, equivalent to 0.074 billion tons of standard coal; the amount of livestock manure resources is about 0.13 billion tons of standard coal; the amount of municipal refuse is about 0.12 billion tons, and it increases at a rate of $8 \%-10 \%$ per year. Energy crop, with a commercial future, is a kind of biomass energy resource. There are many kinds of energy crops, which are suitable for our country to plant, such as oil crops and some wild plants.

Biomass energy belongs to low carbon energy, which plays an important role in gradually changing China's energy structure dominated by fossil fuels. With the increasing attention of international community to reducing the emission of greenhouse gas, vigorously developing biomass energy resources has a great significance to improve China's energy structure dominated by fossil fuels, especially provide clean and convenient energy for rural areas, according to local conditions.

\section{Low Carbon Contribution Degree And Its Evaluation Method}

\subsection{Definition of Low Carbon Contribution Degree.}

In economics, contribution degree is a commonly used indicator to analyze economic benefits, and it is also used to analyze the importance of various factors, which play roles in economic growth; in accounting, when calculating the cost, the contribution degree is refers to the difference of commodity price and variable cost. This report focuses on the low carbon benefits of low carbon 
power technology, and puts forward the definition of low carbon contribution degree, based on the theoretical knowledge of contribution degree in economics and accounting.

Low carbon contribution degree is an evaluation index, used to measure emission reduction benefits of some low carbon power technology. Referring to the calculation method of contribution degree in accounting, this paper defines the low carbon contribution degree of low carbon power technology as follows: low carbon contribution degree is carbon emission reduction benefit, which can be obtained by comparing some low carbon power technology and conventional thermal power technology, through a complete set of accounting measurement system. It is shown as follows:

Low carbon contribution degree $=$ Carbon emission reduction coefficient of conventional thermal power technology - Carbon emission reduction coefficient of some low carbon power technology

\subsection{Life Cycle Analysis Method.}

The paper will calculates and analyzes the low carbon contribution degree of various low carbon power technologies, based on the life cycle analysis method.

Life cycle analysis (LCA) method detailed studies the demand of energy and the wastes discharged by the use and activity of raw materials in its life cycle, including the resource reuse of raw material, manufacturing/processing, distribution, use/ recycling/maintenance and later waste disposal. On the basis, the comparison of final schemes includes the identification and reduction of energy demand, the use of raw materials, waste discharge and regeneration, resource conservation and so on.

The definitions about life cycle analysis of the International Standardization Organization (ISO) and the International Society of Environmental Toxicology and Chemistry (SETAC) are the most authoritative. ISO defines it as: it is a method to summarize and evaluate the caused and potential impact of all inputs and outputs to the environment of a product (or service) system in its entire life cycle. The inputs are the substance or energy entering a unit process; the substance includes raw materials and products. The outputs are the substance or energy leaving a unit process; the substance includes raw materials, intermediate products, products, emissions, and wastes.

\section{Analysis on the Emission Reduction Contribution Degree of Biomass Power Generation Technology}

\subsection{Evaluation method.}

(1) Life cycle emission inventory of biomass gasification power generation

The application of LCA method to evaluate the low carbon contribution degree of biomass gasification power generation technology needs to clear that which stage in the entire life cycle of biomass gasification power generation would discharge pollutants. The life cycle emission inventory of biomass gasification power generation is shown in figure 1.

(2) Evaluation procedure

After identifying the life cycle emissions of biomass gasification power generation, the low carbon contribution degree is evaluated from the following three steps:

1) Determine the input and output of biomass gasification power generation system. In the determined biomass gasification power generation system, the system input and output of functional units in each stage are established on the basis of the energy and substance conservation, and then, the consumption and emission inventories of the biomass power generation system are obtained.

2) Calculate the discharge of $\mathrm{CO}_{2}$ from biomass power generation system. The calculation formula is following:

$$
S_{c o_{2}}=\sum A_{i, j}+\left(\sum F_{i, j}\right) / L
$$

Where, $S_{\mathrm{CO}_{2}}$ is the discharge of $\mathrm{CO}_{2}$ from biomass power generation system in the life cycle; $j$ is some unit stage in the system; $A_{i j}$ is the $\mathrm{i}$-th input and output in $\mathrm{j}$-th unit stage; $F_{i j}$ is the $\mathrm{i}$-th input and output at the beginning of $\mathrm{j}$-th unit stage, no more addition later; $L$ is life cycle of the system. 


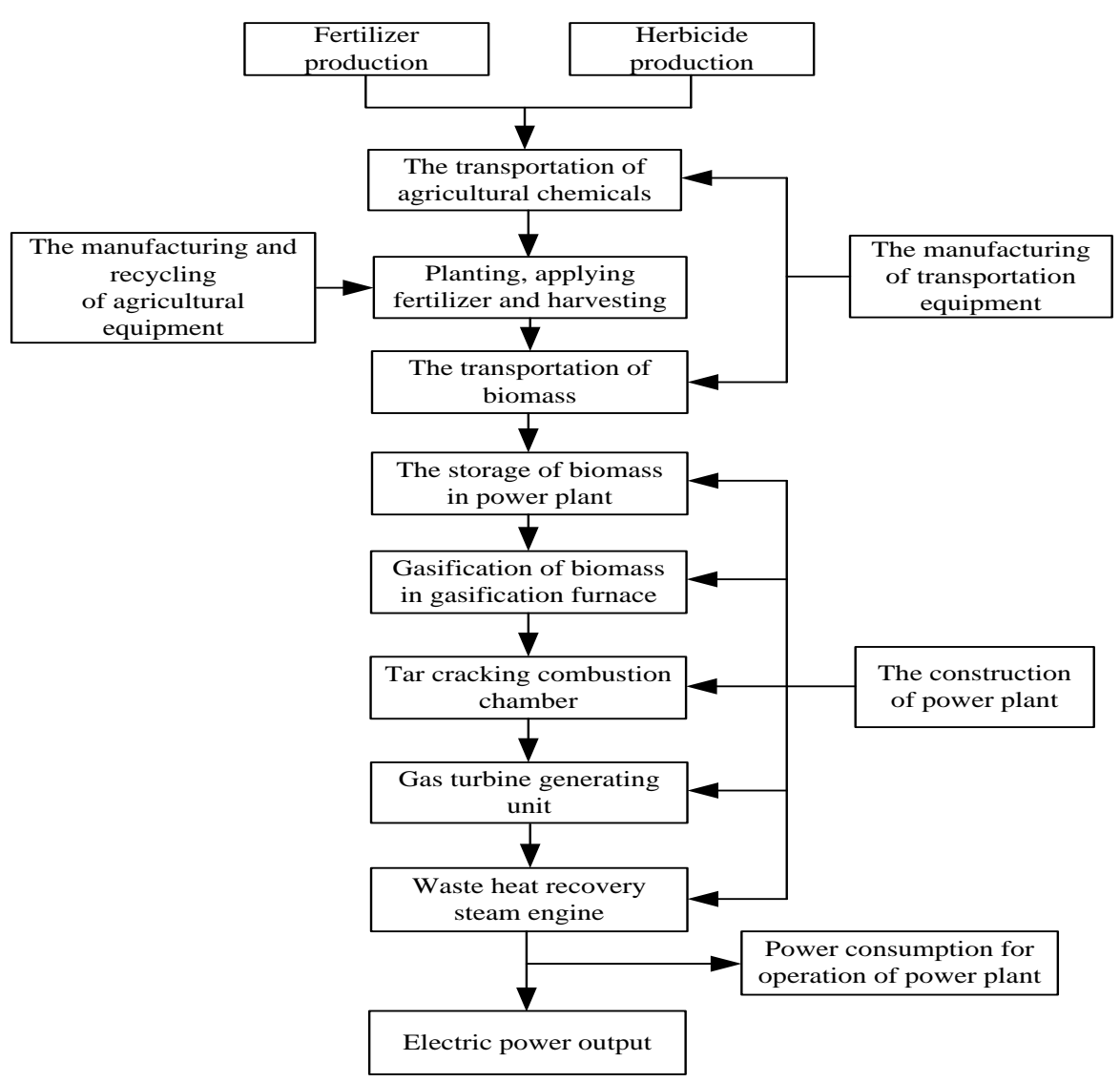

Fig. 1 Life cycle emission inventory of biomass gasification power generation

3) Calculate the emission coefficient of $\mathrm{CO}_{2}$ of biomass power generation system. Considering that the biomass power generation system can generate 10 thousand $\mathrm{kWh}, \mathrm{CO}_{2}$ emissions divided by generating capacity is the emission coefficient of $\mathrm{CO}_{2}$.

\subsection{Empirical Analysis.}

(1) Overview of the project

The report takes $1 \mathrm{MW}$ fluidized bed husk gasification power generation system as the specific study object, whose annual generating capacity is 4.5 million $\mathrm{kWh}$; the gasification efficiency is $78 \%$; the generation efficiency is range from $15 \%$ to $18 \%$; the consumption of husk is $116 \mathrm{~kg} / \mathrm{kWh}$; the collect radius of husk is about $50 \mathrm{~km}$. And the consumption material of power plant equipment is about 110t, in which the steel accounts for 64\%; iron accounts for 14\%; copper accounts for 6\%; thermal insulating refractory material accounts for $15 \%$. Assuming the life of power plant is 20 years, calculate and analyze the environmental impact caused by generating every 10 thousand $\mathrm{kWh}$ of the system, that is, the functional unit of the system is 10 thousand $\mathrm{kWh}$.

(2) Calculation of the emission coefficient of $\mathrm{CO}_{2}$

According to the evaluation steps, the emissions of $\mathrm{CO}_{2}$ are obtained after inputting relevant data. As shown in table 1.

Table 1 The system input and $\mathrm{CO}_{2}$ output of husk biomass power generation system

\begin{tabular}{cccc}
\hline & Item & Mean value & Unit \\
\hline & Husk & 16 & $\mathrm{t}$ \\
& Conventional power & 0.053 & $\mathrm{GJ}$ \\
Crude oil & 12.6 & $\mathrm{GJ}$ \\
Input & Fuel oil & 0.26 & $\mathrm{GJ}$ \\
& Gasoline & 3.6 & $\mathrm{GJ}$ \\
& Diesel oil & 2.4 & $\mathrm{GJ}$ \\
& Pipeline transport & 0.12 & $\mathrm{kt} \cdot \mathrm{km}$ \\
& Water & 19.1 & $\mathrm{t}$ \\
\hline Output & $\mathrm{CO}_{2}$ (life cycle) & 7745 & $\mathrm{~kg}$ \\
\hline
\end{tabular}


Note: the above data is only part of the main input data and $\mathrm{CO}_{2}$ output data of biomass gasification power generation system.

It can be known from table 1, when biomass gasification power generation generates 10 thousand $\mathrm{kWh}$, in the entire life cycle, it would produce $7745 \mathrm{~kg} \mathrm{CO}_{2}$, so the emission coefficient of $\mathrm{CO}_{2}$ of biomass gasification power generation is $774.5 \mathrm{gCO}_{2} / \mathrm{kWh}$.

The related studies at home and abroad show that the emission coefficient of $\mathrm{CO}_{2}$ of biomass gasification power generation is range from $141.97 \mathrm{gCO}_{2} / \mathrm{kWh}$ to $779 \mathrm{gCO}_{2} / \mathrm{kWh}$. Although the experimental data obtained in this paper is limited, the emission coefficient of $\mathrm{CO}_{2}$ of biomass gasification power generation based on the experimental data is still within a reasonable range of $774.5 \mathrm{gCO}_{2} / \mathrm{kWh}$.

\section{Analysis on Emission Reduction Cost-effectiveness of Biomass Power Generation}

Biomass energy plays a very important role in the formation and development of circular economy. Biomass energy is generally regarded as the world's largest renewable energy resource. It is of great significance to China's energy security and environment security, so more and more attention is being paid to biomass energy.

\subsection{Determine the boundary of life cycle.}

The power generation cost of biomass gasification power plant is composed of equipment depreciation, repair cost, operation cost, interest and biomass fuel cost. Biomass fuel cost constitutes the major part of power generation cost, in general, it could account for more than $40 \%$, followed by operation cost, accounting for about $20 \%$. The main factors that impact the economy of biomass gasification power generation are the unit capacity, fuel cost and running time. While the transportation of raw material, raw material storage and complementary are the important factors that affect the scale of biomass power generation and the cost of power production.

Production costs include initial investment and operation costs. Generally, the cost of unit energy production capacity (Yuan $/ \mathrm{kWh}$ ) is used to estimate the production cost. The initial investment is the construction cost of energy supply system, which is the problem that is often given priority when making decisions. Operation costs include fuel cost, power cost, water rate, material cost, infrastructure depreciation cost, major repair cost, wages, employee benefits and other expenses. The operation and maintenance cost mainly depends on the power plant's technical performance, safety rules and regulations, and necessary human resources. Operation costs are divided into two parts: fixed costs, including the cost of labor and insurance; variable costs, related to the costs of fuel storage, power supply, repair and maintenance and others.

\subsection{Determine the boundary of life cycle.}

(1) Life cycle cost

The technical economic analysis method is used to analyze the production costs. The technical economic analysis method has many kinds. According to whether considering the time factor or not, it can be divided into two kinds: static analysis method and dynamic analysis method. In this part, annual cost method of the dynamic analysis method is used to analyze production costs. The annual cost method uses the capital recovery formula, the initial investment is equally converted to each year, and then, add the operation costs of the year. The formula is as follows:

$$
A_{C}=\frac{C_{i}\left[\frac{i(1+i)^{n}}{(1+i)^{n}-1}\right]+C_{k}}{X}
$$

Where, $A_{C}$ is production costs of power generation, Yuan $/ \mathrm{kWh} ; C_{i}$ is the initial investment, Yuan; $C_{k}$ is operation and maintenance cost, Yuan; $n$ is economic life set by the system, year; $I$ is capital recovery coefficient, which take the value of $10 \% ; X$ is annual energy output, $\mathrm{kWh}$.

$$
\pi_{L C C}=A_{C} \cdot X \cdot n \cdot h
$$

Where, $\pi_{L C C}$ is life cycle cost of power generation. 
(2) Life cycle benefit

The generation income is just considered when calculating life cycle benefit, which can be obtained by generating capacities multiplying feed-in tariff; represented by $M_{\text {in }}$, the formula is as follows:

$$
M_{\text {in }}=E_{e} \cdot P_{E}
$$

Where, $E_{e}$ is generating capacity in the life cycle of power plant; $P_{E}$ is feed-in tariff.

(3) Benefit cost ratio

The benefit cost ratio of life cycle is the ratio of benefit and cost of the system; represented by $\xi_{L C A}$, the formula is as follows:

$$
\xi_{\mathrm{LCA}}=\frac{M_{i n}}{\pi_{L C C}}
$$

\subsection{Empirical analysis.}

The power generation cost of biomass gasification power plant is composed of equipment depreciation, repair cost, operation cost, interest and biomass fuel cost. Biomass fuel cost constitutes the major part of power generation cost, in general, it could account for more than $40 \%$, followed by operation cost, accounting for about $20 \%$. The main factors that impact the economy of biomass gasification power generation are the unit capacity, fuel cost and running time. While the transportation of raw material, raw material storage and complementary are the important factors that affect the scale of biomass power generation and the cost of power production. Referring to literature relevant to analysis of biomass gasification cost, the generation costs of $1 \mathrm{MW}$ biomass gasification power are shown in the table 2 .

Select $1 \mathrm{MW}$ medium biomass gasification power generation system, according to the costs of biomass gasification power in table 2, it can be seen that the initial investment of the biomass gasification power generation is $2900 \mathrm{Yuan} / \mathrm{kW}$, operation cost is $0.247 \mathrm{Yuan} / \mathrm{kWh}$; the annual operation time of unit is $6000 \mathrm{~h}$, and the years of depreciation are 25 years; feed-in tariff is 0.55 Yuan $/ \mathrm{kWh}$. Based on the above data table, the unit production cost of biomass gasification power generation can be obtained by the formula (2). It is $0.30 \mathrm{Yuan} / \mathrm{kWh}$

Table 2 Raw Data of biomass gasification power generation

\begin{tabular}{ccc}
\hline & Parameter & $1 \mathrm{MW}$ \\
\hline & Total investment & 290 \\
Equipment investment & 207 \\
& Infrastructure investment & 15 \\
& Installation and commissioning cost & 15 \\
& Fuel transportation cost & 8 \\
& Sewage disposal & 45 \\
& Running days & 250 \\
Operation costs & The number of operation workers & 12 \\
& Gross generation & 600 \\
& Raw material cost & 82 \\
& Labor cost & 21.6 \\
& Maintenance cost & 31 \\
& Office expenses & 13.5 \\
\hline
\end{tabular}

According to formula (3-5), generation cost, generation benefit and benefit cost ratio of biomass gasification power generation can be obtained, shown in table 3 .

Table 3 Cost and benefit of biomass gasification power plant

\begin{tabular}{cc}
\hline \multicolumn{2}{c}{ Biomass gasification } \\
\hline Cost/yuan & $4.5 \times 10^{7}$ \\
Benefit/yuan & $8.25 \times 10^{7}$ \\
Benefit cost ratio & 1.8333 \\
\hline
\end{tabular}


In the current economic environment, the depreciation periods are 25 years, the generation cost of $1 \mathrm{MW}$ medium biomass gasification power generation system is $4.5 \times 107$ Yuan. The unit generation cost is $0.30 \mathrm{Yuan} / \mathrm{kWh}$; benefit is $8.25 \times 107$ Yuan; and the benefit cost ratio is 1.8333 .

The unit price of biomass is an important factor affecting the economy of biomass gasification power generation. The increase of unit price of biomass will reduce the economy of the biomass gasification power generation project, shown as the increase of power generation cost. In the initial stage of biomass power generation industry, due to the inherent defects in externality and public resources of market, and China's limited efforts about pollution control at present, the cost benefit ratio of biomass power generation enterprises is much higher than coal-fired power generation enterprises. The increase of benefit mainly depends on the support of government policy. In the initial stage of green power generation, the calculability of cost and the uncertainty of benefit often lead to the lack of support for green power technology and the relative backwardness of policy making.

\section{Conclusion}

Firstly, this paper puts forward the low carbon contribution degree of biomass power generation and its evaluation method; secondly, with the theoretical and empirical combination, it analyzes the emission reduction contribution degree of biomass power generation technology; finally, the emission reduction cost-effectiveness of biomass power generation are comprehensively studied. And this paper lays the theoretical foundation for the biomass power generation project to carry out.

In the process of analyzing emission reduction contribution degree of biomass power generation technology, based on the life cycle theory, this paper firstly puts forward emission inventories in the life cycle of biomass gasification power generation technology; and then, it lists evaluation steps; finally, based on specific project, $\mathrm{CO}_{2}$ emission coefficient of biomass gasification power generation technology is $774.5 \mathrm{CO}_{2} / \mathrm{kWh}$, within a reasonable range.

It can be known from the analysis of emission reduction cost-effectiveness of biomass power generation: the application of biomass power generation technology in China is still in the initial stage. There are many difficulties need to be overcame. After analysis of cost-effectiveness of enterprise and government in the initial stage of biomass power generation from all aspects, it is thought that the government must increase efforts to support in order to make more power enterprises use biomass fuels in the process of power generation.

\section{Acknowledgements}

This paper was supported by Science and Technology Project of State Grid Corporation of China (Research on the effects of air pollution prevention and control on the power supply and demand of Beijing-Tianjin-Hebei Region).

\section{References}

[1] Ruijian Wu. Study on biomass energy production utilization model based on circular economy [D]. Zhengzhou: Henan Agricultural University, 2011.

[2] Yanxu Xie. Strategic research on the technological innovation of China's new energy [D]. Jinzhou: BOHAI University, 2014.

[3] Changbo Che, Jihua Yuan. Developing trend of biomass energy sources in the world [J]. Natural Gas Industry, 2011(1): 105.

[4] Yingzi Chen, Yutong Li. Research on low-carbon economy and China's regional energy utilization [J]. Jilin University Journal Social Sciences Edition, 2009(2): 66-73.

[5] Gesheng Huang, Zhenyu Li, et al. Development status and prospects for second-generation biodiesel technology [J]. Modern Chemical Industry, 2012, 32(6): 6-10. 
[6] Jichuan Li. Research and analysis of fuel system of two biomass power plant in Germany [J]. Science and Technology for Development, 2010(10): 38, 58.

[7] Zhijun Li. Biomass direct combustion power generation in China: present situation, problems and policy suggestions [J]. Technology Economics, 2008, 27(9): 34-37.

[8] Dan Men. Research on fiscal expenditure policy for the development of new energy in the United States [J]. Ecological Economy, 2013(4): 81.

[9] Bill Richardson .Stop the politics and adopt a national energy plan [J].Financial Time, March 22, 2012. 